\title{
Public vs. Private Perceptions on Hiring of an External Program Manager
}

\author{
William Rasdorf, Ph.D., P.E., F.ASCE, Barton Grasso, A.M.ASCE, Mark Bridgers
}

\section{Outline*}

\author{
Abstract \\ Introduction \\ Relevance to the Construction Community \\ Background \\ Research Methodology and Survey Development \\ Survey Participants \\ Survey Dissemination \\ Survey Results \\ Survey Demographics and Market Sectors \\ Survey Representation of the Construction Industry \\ Results \\ Respondent Classification \\ Extent of Use of an External Program Manager \\ Fees \\ Types of Firms Used for Program Management \\ Factors Considered When Hiring a Program Manager \\ Owner Organizational Models for Incorporating Program Management \\ Conclusions \\ Fees \\ Type of Service Provider \\ Selection Criteria \\ Model \\ Recommendations \\ Acknowledgement \\ References
}

*The outline is provided only for the convenience of the reviewers. 


\title{
Public vs. Private Perceptions on Hiring of an External Program Manager
}

\author{
William Rasdorf, Ph.D., P.E., F.ASCE, Barton Grasso, A.M.ASCE, Mark Bridgers
}

\section{INTRODUCTION}

Construction owners were the first program managers and many still perform a large majority of the management of their construction program in-house. However, a service offering has emerged within the construction industry that covers the management of multiple projects across all functions of the construction life-cycle. This service offering is commonly referred to as program management. Program management can be performed either by the internal staff of a construction owner, by an external staff hired by the construction owner, or in some combination of both. This paper focuses on the use of an external staff to manage a construction program, specifically the hiring of an external program manager.

Program management is defined as:

"The unified management of a capital improvement program consisting of one or more projects from inception to completion. Comprehensive construction management principles are used to integrate the different facets of the construction process - planning, design, procurement, construction, and activation - for the purpose of providing standardized technical and management expertise on each project" [Bridgers, 2006].

Program management is classified as a management technique. Management techniques are different from project delivery methods. A project delivery method is defined as, "a comprehensive process of assigning the contractual responsibilities for designing and constructing a project" [Kenig et al., 2004]. A management technique or method is defined as, "a method of managing design and construction services" [Kenig et al., 2004].

A common misconception exists within the construction industry that management techniques and project delivery methods are one in the same. Because of this misconception a question arises as to the true extent of the use of program management in the construction industry. The purpose of this study was to attempt to determine this extent. A survey was conducted to identify some of the current practices with respect to hiring an external program manager. The results of the survey and the subsequent analysis and conclusions are presented in this paper. This paper addresses four specific topics related to the hiring of an external program manager:

- Fees

- Type of service provider

- Selection criteria

- Organizational models

This paper should aid the reader in understanding the process of hiring an external program manager. It is intended to convey what is presently happening in this segment of the construction industry with respect to program management. The paper provides specific recommendations for both industry and research to better define and standardize program management fees and services and certification. Thus, we believe there are straight forward and 
specific steps that can be taken to clarify program management and to enhance this aspect of the construction industry.

\section{RELEVANCE TO THE CONSTRUCTION COMMUNITY}

One of the most newsworthy items in the world of business today is outsourcing. The primary focus of the discussions in the media, however, have been on outsourcing some portion of the work currently performed by American companies and personnel to sources outside of the U.S. and the resulting impact of that outsourcing on the American job market. The subject of this paper is also outsourcing, but the paper does not focus on the geographic location of the service provider. Instead, it focuses on the nature and extent of the service and its prevalence in the construction industry. The service addressed is program management.

Outsourcing is a timely and important subject that is highly relevant to the construction industry. Because of its nature, outsourcing is an inherent element of construction. There is always some (at times all of the work) aspect of the work that is sub contracted and there are materials of construction and engineered materials that are manufactured, built, or assembled by others. Over time a shift in emphasis has occurred from work performance to the outsourcing of the process of construction. That shift is now extending to the various management areas of construction, to the extent of transferring to outside sources all activities related to the built physical plant of an owner.

The implications of outsourcing are significant and the opportunity for growth in this relatively new construction related arena is emerging. Thus, construction industry insight is needed into the extent of outsourcing, how outsourcing of the entire program of construction (for an owner) might be done, and the extent to which this is occurring. This paper addresses the latter two points. The extent of outsourcing was discussed earlier [Rasdorf, 2008]. There, design and construction were identified as the most heavily outsourced project activities and phases $(75 \%)$ while all other activities ranged much lower (30-40\%) except for maintenance and operations (just under 30\%).

\section{BACKGROUND}

Program management is a popular term now used in the construction industry for the broad management of multiple projects. It is closely related to construction management, another management technique used within the construction industry. The current Construction Management Association of America (CMAA) definition of construction management is, "a professional service that applies effective management techniques to the planning, design, and construction of a project from inception to completion for the purpose of controlling time, cost and quality" [CMAA, 2006]. Program management is in many ways the application of construction management to multiple facilities or extremely large projects.

The idea behind program management is that the management of multiple projects will lead to improved efficiencies in the technical and management aspects of each project within the construction program. This improved efficiency will in turn lead to improved performance. According to Kumaraswamy, "Worldwide initiatives to improve construction industry performance converge on the common need for more effective team-working. This is increasingly critical in the context of complex multi-participant construction projects" 
[Kumaraswamy et. al., 2005]. It is the job of the program manager to create such efficiencies and also to integrate and manage the large number of parties involved throughout the construction process.

A program manager must have the capability to handle multiple projects and large project teams, and at the same time serve the owner's interest. Typical construction methods use the design professional to act in the owner's interest. But there are issues that revolve around the use of a design professional in that role, among them:

- The lack of expertise of the design professional regarding the entire construction process.

- The designers reluctance to serve as protector of the owners financial interest.

- The designer's role of administrator does not coincide with their design responsibilities [Gordon, 1994].

In deciding whether to consider the use of a program manager, an owner must evaluate the same set of criteria that would normally be used to make decisions on what contracting method to use on individual projects. These criteria include:

- Construction sophistication

- Current capabilities

- Risk aversion

- Restrictions on methods (typically laws)

- Other external factors [Gordon, 1994]

Owners have begun to push for more services from the firms that are delivering and managing their construction projects. In a recent American Institute of Architects (AIA) document, The Client Experience, design professionals have been encouraged to expand their service offerings to the owner [Hansen and Vanegas, 2005]. Many service providers have responded with a technique now referred to as program management. Limited research exists, however, on program management, and research pertaining to the use of an external program manager has been critically limited. This paper seeks to partially fill this void.

\section{RESEARCH METHODOLOGY AND SURVEY DEVELOPMENT}

Due to the lack of related studies and limited research on the subject of program management, a survey was deemed to be appropriate for gaining insight into current industry practices regarding the hiring of an external program manager. In conjunction with FMI Corporation, a construction consulting firm, and the Construction Management Association of America (CMAA), a survey was developed that focused on multiple topics relating to the concept of program management, including the use of an external program manager.

The 2006 FMI/CMAA Survey of Owners was the seventh in a series of annual surveys developed, executed, analyzed, and reported on by FMI and CMAA. Past surveys of owners have historically focused on construction management. The seventh survey instrument, which focuses on program management, was developed through a series of meetings with a focus group of industry professionals. The focus group consisted of members who were both knowledgeable and experienced within the realm of program management in construction. 


\section{Survey Participants}

The targeted participants for the survey were owners of construction. In order to reach the largest number of possible survey respondents several professional organizations within the construction industry were contacted. Each of the professional organizations represents a large number of construction owners from a broad range of market sectors. Through professional contacts established by FMI and CMAA, the following organizations provided assistance in accessing their membership base for the survey:

- Construction Management Association of America (CMAA)

- Construction Owners Association of America (COAA)

- Construction Users Roundtable (CURT)

- Health Facility Institute (HFI)

- Council of Education Facility Planners International (CEFPI)

All of these organizations agreed to take part in the survey. In addition to the membership base of these professional organizations, contacts within the FMI internal database were also solicited to take part in the survey.

\section{Survey Dissemination}

The survey was disseminated both by a paper copy delivered through standard postal mail and by an internet link to an online version of the survey that was emailed to select participants. A total of about 1,500 surveys were distributed. While the intent in doing so was to achieve wide distribution through appropriate media we were carefully thinking about the comparative response rate. A recent study found that while there are some potentially significant differences between postal, email, and web surveys the representativeness of the sample achieved was improved by using multi-modal survey techniques [Yun and Trumbo, 2000].

Paper copies of the survey instrument were sent to individuals for whom an email address was not available. All other potential survey respondents received an email invitation to participate in the survey. This was done by providing each of the professional organizations with an electronic mail message that included an introductory statement explaining to the target population of construction owners the purpose of the survey and the importance of their involvement. The introductory statement also included a link to the survey's URL address. The responsibility of forwarding the email to their membership base was assumed by the administrative staff of each respective organization. Since each organization was not required to furnish their membership list to us, the full extent of the survey's distribution and the total potential number of respondents was not known.

\section{Survey Results}

The results of the survey were collected through the same medium by which they were distributed. A total of 170 responses to the survey were received. However, the total number of responses for the questions pertaining to the use of an external program manager received a lower response rate than other questions on the survey. This was due to the fact that respondents were only asked to answer those questions if they had actual experience in doing so. A varying number of responses were recorded for the questions related to the hiring of an external program manager with the highest number of responses for any one question being 97. The actual 
number of responses for each individual question is provided (along with a summary of the responses) in the discussion of the following section.

The confidence interval for the survey responses was not calculated. According to Galloway, a confidence interval should not be calculated for a voluntary survey because "a confidence level calculation is not valid for a voluntary survey because underlying factors could exist as to why these companies chose to respond and others did not," [Galloway, 2006]. Furthermore, there were 170 respondents from a population of construction owners estimated to number 1500, a rate too low to guarantee that the survey results can be generalized to the larger population. However, the demographic data collected in the survey suggested that the respondents were representative of the construction industry as a whole. Therefore we believe that the information provided by the survey respondents is a consequential and valid description of their construction management practices.

\section{Survey Demographics and Market Sectors}

Demographic data was collected on the type, market sector, projects started per year, and annual construction expenditures of the construction programs surveyed. The demographic data presented in this paper is that for the 97 organizations that responded to any of the questions related to the hiring of an external program manager. Table 1 presents the percentage breakdown of the 97 survey respondents by organization type who have experience hiring a program manager. Table 2 presents the number of responses and the percentage breakdown of the market sector in which each responding construction program primarily operated.

Table 1 shows an organizational type grouping to differentiate between public and private organizations. The groupings are clear except for the category "quasi-public" which was characterized as private. This category contains organizations such as large port authorities and electric utilities.

Table 1: Survey Respondent Organizational Categories

\begin{tabular}{||l||c|c||}
\hline Organization Type & $\begin{array}{c}\text { Percentage of } \\
\text { Respondents }\end{array}$ & Grouping \\
\hline \hline Private/Closely Held & $8 \%$ & Private \\
\hline Publicly Traded Stock Corporation & $33 \%$ & Private \\
\hline Quasi-Public & $4 \%$ & Private \\
\hline \hline Sub Total (Private) & $\mathbf{4 5 \%}$ & Private \\
\hline \hline Federal Agency & $6 \%$ & Public \\
\hline State Agency & $13 \%$ & Public \\
\hline Municipal Authority & $10 \%$ & Public \\
\hline \hline Sub Total (Public) & $\mathbf{2 9 \%}$ & Public \\
\hline \hline Other & $26 \%$ & Other \\
\hline \hline
\end{tabular}


Table 2 identifies the market sector in which the respondents operate. The sectors can largely be viewed in four primary groups. Standing alone at the top is education (33\%). It is closely followed by two other clearly discernable sectors - energy and private office and professional (approximately $40 \%$ combined). The third major grouping consists of public service sectors and includes Water Supply/Waste Water Facilities, Public Safety, Administrative, and Other, Highways and Streets, and Hospitals and Nursing Homes (46\% combined). This leaves a final collection of market sectors representing a great diversity of smaller market segments in which the respondents work. Note that these percentages do not total to $100 \%$ as some organizations participate in multiple market segments.

Table 2: Market Sectors of Survey Respondents

\begin{tabular}{||l||c|c||}
\hline Description & No of Selections & Percentage* \\
\hline \hline Education & 32 & $33.0 \%$ \\
\hline Energy & 21 & $21.6 \%$ \\
\hline Private Office and Professional & 18 & $18.6 \%$ \\
\hline Other & 18 & $18.6 \%$ \\
\hline Manufacturing & 13 & $13.4 \%$ \\
\hline Water Supply/Waste Water Facilities & 13 & $13.4 \%$ \\
\hline Public Safety, Administrative, and Other & 12 & $12.4 \%$ \\
\hline Highways and Streets & 11 & $11.3 \%$ \\
\hline Hospitals and Nursing Homes & 9 & $9.3 \%$ \\
\hline Commercial & 6 & $6.2 \%$ \\
\hline Telecommunications & 6 & $6.2 \%$ \\
\hline Amusements and Recreation & 4 & $4.1 \%$ \\
\hline Military Facilities & 4 & $4.1 \%$ \\
\hline Churches/Houses of Worship & 2 & $2.1 \%$ \\
\hline Conservation and Development & 2 & $2.1 \%$ \\
\hline Hotels and Motels & 2 & $2.1 \%$ \\
\hline \hline
\end{tabular}

*This rate is calculated using the total number of responses (97)

\section{Survey Representation of the Construction Industry}

The data obtained from the survey respondents on annual construction expenditure was used to determine the percentage of the construction industry represented by the survey respondents. The total amount of construction expenditure for all survey respondents was calculated by assigning mid-points to each specific range of construction spending, and then multiplying the total number of respondents by the midpoint of each range. The respondents to the survey were found to have cumulative total annual construction expenditure of about $\$ 75$ Billion. However the cumulative total annual construction expenditure for those respondents who had experience with hiring a program manager was approximately $\$ 51$ Billion. 
Considering that the construction market totaled \$1.14 trillion in 2005 [Simonson, 2006] and the non-residential market accounted for 51.7 percent of industry revenues, the non-residential construction market put in place an estimated $\$ 590$ billion in 2005 [Datamonitor, 2006]. The 170 survey respondents, constituting 11 percent of the population of construction owners, account for an estimated 9 percent of the overall non-residential construction dollars spent in the United States in 2006. Table 3 presents the results and calculations for the data obtained on annual construction expenditures.

Table 3: Annual Construction Expenditures for Survey Respondents

\begin{tabular}{||c||c|c|c||}
\hline $\begin{array}{c}\text { Annual } \\
\text { Construction } \\
\text { Spend }\end{array}$ & $\begin{array}{c}\text { Number of } \\
\text { Selections }\end{array}$ & $\begin{array}{c}\text { Mid-Point (in } \\
\text { Millions) }\end{array}$ & $\begin{array}{c}\text { Total Amount of } \\
\text { Construction Spend } \\
\text { (in Millions) }\end{array}$ \\
\hline \hline$<\$ 1 \mathrm{M}$ & 1 & 0.5 & 0.5 \\
\hline$\$ 1-\$ 25 \mathrm{M}$ & 15 & 13 & 195 \\
\hline$\$ 25-\$ 100 \mathrm{M}$ & 22 & 63 & 1,386 \\
\hline$\$ 100-\$ 500 \mathrm{M}$ & 31 & 300 & 9,300 \\
\hline$\$ 500 \mathrm{M}-\$ 1 \mathrm{~B}$ & 11 & 750 & 8,250 \\
\hline$>\$ 1 \mathrm{~B}$ & 16 & 2,000 & 32,000 \\
\hline \hline Totals & $\mathbf{9 6}$ & N/A & $\mathbf{5 1 , 1 3 2}$ \\
\hline
\end{tabular}

\section{RESULTS}

The survey contained multiple questions related to the outsourcing of construction programs, to the sourcing strategy of construction owners, to defining the role of a program manager, and to the hiring of a program manager. This paper reviews the results of the questions related to the hiring of an external program manager. The reader should note, however, that due to the differences in procurement practices of public and private owners, the results of the survey are separately presented in terms of both the public and private responses. The response totals for the entire survey population can be obtained by adding the public and private response totals. The following sections detail the results of these questions.

\section{Respondent Classification}

Due to the depth of material covered by the survey, the questions pertaining to the hiring of an external program manager were included in a separate section positioned at the end of the survey. As noted earlier, this question set was not completed by all survey respondents. Whether or not the respondents answered the questions was based on the respondent's experience with the use of an external program manager. A total of 57.1\% (97/170) of the survey respondents reported having experience in hiring an external program manager.

In order to gain further insight into any trends, the 97 respondents with experience in hiring an external program manager, were reclassified as either public or private. To classify a responding organization as public or private an analysis of the demographic question pertaining to the type of firm (see Table 1) was performed. As a result, all respondents who classified themselves as 'other' were able to be reclassified as either one of the existing firm types or as a new firm type titled 'private not for profit.' Using the detailed classifications of each organization, all 
responses were classified as either strictly private or public. Federal agency, state agency, and municipal authority were classified as public organizations while private not for profit, private/closely held, publicly traded stock corporations, and quasi-public were classified as private organizations.

Table 4 presents the results of classifying each category as public or private. The percentages for the total number of responses for both the private and public categories are presented in Table 4. Fifty-one percent (49/97) were classified as private, while 49 percent (48/97) were classified as public.

Table 4: Private and Public Classification of Construction Ownership

\begin{tabular}{|c|c|c|c|c|c|c|c|}
\hline \multirow[b]{2}{*}{$\begin{array}{l}\text { Reclassified } \\
\text { Categories }\end{array}$} & \multicolumn{4}{|c|}{ Private } & \multicolumn{3}{|c|}{ Public } \\
\hline & $\begin{array}{l}\text { Private or } \\
\text { closely held }\end{array}$ & $\begin{array}{l}\text { Publicly } \\
\text { traded stock } \\
\text { corporation }\end{array}$ & $\begin{array}{l}\text { Quasi- } \\
\text { public }\end{array}$ & $\begin{array}{l}\text { Private } \\
\text { not for } \\
\text { profit }\end{array}$ & $\begin{array}{l}\text { Municipal } \\
\text { authority }\end{array}$ & $\begin{array}{c}\text { State } \\
\text { agency }\end{array}$ & $\begin{array}{l}\text { Federal } \\
\text { agency }\end{array}$ \\
\hline Number of Responses & 8 & 31 & 4 & 6 & 23 & 18 & 7 \\
\hline $\begin{array}{l}\text { Total Number of } \\
\text { Responses }\end{array}$ & \multicolumn{4}{|c|}{49} & \multicolumn{3}{|c|}{48} \\
\hline $\begin{array}{l}\text { Percentage of Total } \\
\text { Responses }\end{array}$ & \multicolumn{4}{|c|}{$51 \%$} & \multicolumn{3}{|c|}{$49 \%$} \\
\hline
\end{tabular}

\section{Extent of Use of an External Program Manager}

A review of the demographic data for the 97 respondents compared to the entire survey population provides further insight into the use of an external program manager. The number of public and private firms responding to the entire survey was 99 and 71 respectively. The number of public and private firms that responded to the final question set was 48 and 49 respectively. The percentage of respondents from the public sector who reported having experience in hiring a program manager was about half at $48.5 \%$ (48/99). The percentage of respondents from the private sector who reported having experience with hiring an external program manager was about two thirds, or $69.0 \%$ (49/71), which was $20.5 \%$ higher than that of the public sector.

Also, as Table 1 showed earlier, a review of the type of firms who appeared to have experience with hiring a program manager expressed trends (These trends are based on the unclassified responses for organization type). Publicly traded stock corporations accounted for 33\% of the total number of respondents who reported having experience with hiring an external program manager while making up $27 \%$ of the entire survey population (170 respondents). Municipal authorities represented only $10 \%$ of those respondents having experience with hiring an external program manager, while representing $16 \%$ of the entire survey population. All other classifications of firms remained fairly consistent between their hiring experience and their demographic market share. Table 5 helps to illustrate the percentage of respondents that reported having experience with hiring an external program manager to the overall percentage of respondents to the survey. 
Table 5: Trends in the Frequency of Different Types of Firms with Experience in Hiring an External Program Manager

\begin{tabular}{||c||c|c|c||}
\hline Organization Type & $\begin{array}{c}\text { Percentage of } \\
\text { Respondents for } \\
\text { Entire Survey }\end{array}$ & $\begin{array}{c}\text { Percentage of } \\
\text { Respondents with } \\
\text { Experience Hiring a PM }\end{array}$ & Difference \\
\hline \multicolumn{3}{|c|}{ Private } \\
\hline \hline Private/Closely Held & $5 \%$ & $8 \%$ & $3 \%$ \\
\hline Publicly Traded Stock Corporation & $27 \%$ & $33 \%$ & $6 \%$ \\
\hline Quasi-Public & $5 \%$ & $4 \%$ & $-1 \%$ \\
\hline \hline \multicolumn{2}{|c|}{ Public } & $6 \%$ & $-2 \%$ \\
\hline \hline Federal Agency & $8 \%$ & $13 \%$ & $-1 \%$ \\
\hline State Agency & $14 \%$ & $10 \%$ & $-6 \%$ \\
\hline Municipal Authority & $16 \%$ & $26 \%$ & $0 \%$ \\
\hline Other & $26 \%$ & & \\
\hline \hline
\end{tabular}

\section{Fees}

One of the survey questions was directed at determining the costs for hiring an external program manager. A total of 64 responses were recorded. The responses were standardized so that an average could be calculated. Some responses needed to be discarded. The response was asked to be given in a percentage format. Responses that deviated from this format were removed when calculating the average fee for an external program manager.

Following the removal of responses, a total of 58 remaining responses were used to calculate an average fee. The survey data shows that the public sector is paying a smaller fee for the services of an external program manager. The average cost of hiring an external program manager for the public sectors (which was based on a total of 34 respondents) was found to be 5.4 percent of the total program value. The average cost for the private sector (which was based on 24 respondents) was found to be 6.8 percent of the total program value.

\section{Types of Firms Used for Program Management}

Another interesting question was what type of firm is typically used by owners to manage their construction program. Respondents were given the option of choosing from the types of firms listed in Figure 1 including the option of selecting their own internal staff. Again, of the 97 responses, 49 were from the public sector and 48 were from the private sector.

The highest percentage of public sector respondents, 36.7 percent (18/49), identified their internal staff as their primary provider. The highest percentage of private sector respondents, 39.6 percent (19/48), identified a construction management firm (agency) as their primary provider followed by their own internal staff (31.3\%). Figure 1 shows the number of respondents that selected each type of provider within the public and private sector.

A review of the responses to this question suggests that the private sector respondents are far more apt to use a construction management firm to manage their construction program as opposed to the public sector which is more apt to use a program management firm. But despite 
this difference, a large number of both public and private sector respondents use internal staff to manage their construction programs.

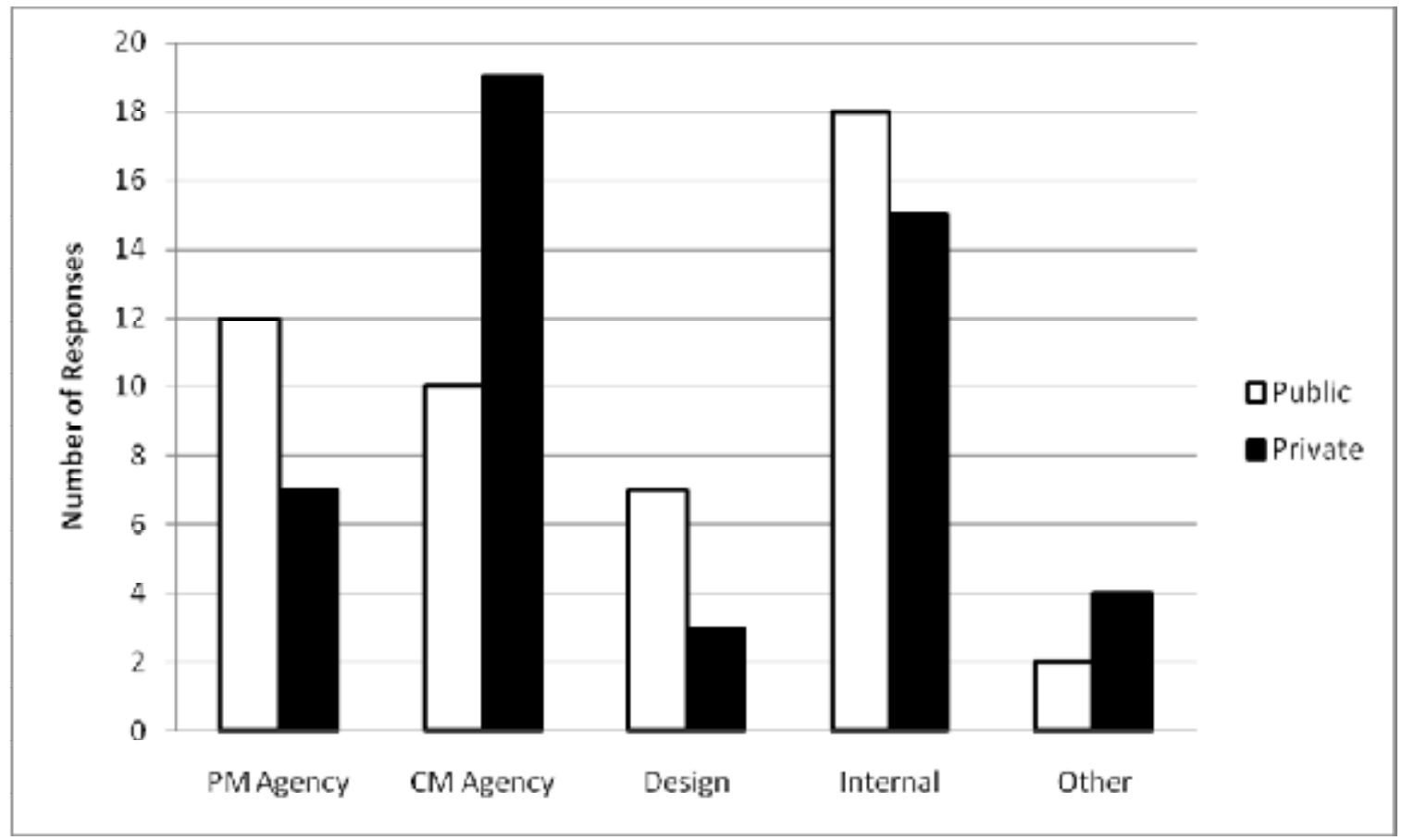

Figure 1: Firms Used Most Often to Manage a Construction Program

\section{Factors Considered When Hiring a Program Manager}

Another research goal was to determine the factors most often considered in hiring an external program manager. Respondents were asked to rate a series of different factors on a scale of 0 to 100 with 0 meaning the factor was never considered and 100 meaning the factor was strongly considered. Again, the responses were segregated by the public and private sectors. Of the 90 total responses, 48 were from the public sector and 42 were from the private sector. The results are shown in Table 6.

The top three highest rated factors considered in hiring an external program manager were the same for both the public and private sectors and included the following:

- Experience with similar projects/programs

- Projects and programs consistently delivered on time

- Individual lead program manager

The lowest rated factors differed slightly between the public and private sectors. The public sector respondents reported that issues related to costs were some of the least considered factors in hiring an external program manager. The issues related to costs that were rated the lowest by the public sector included: 
- Savings in construction costs

- Greater economies of scale/efficiencies/integration

- Savings in design costs

Table 6: Functions Considered when Hiring a Program Manager

\begin{tabular}{||l||c|c||}
\hline \hline Function & Public & Private \\
\hline \hline Experience with similar projects/programs & $85.1 \%$ & $87.4 \%$ \\
\hline Projects and programs consistently delivered on time & $82.6 \%$ & $85.7 \%$ \\
\hline Individual lead program manager & $81.3 \%$ & $84.9 \%$ \\
\hline Past experience with your organization & $76.4 \%$ & $74.2 \%$ \\
\hline Program controls & $74.3 \%$ & $81.0 \%$ \\
\hline Depth on the bench & $72.2 \%$ & $76.2 \%$ \\
\hline Technical approach & $71.9 \%$ & $74.6 \%$ \\
\hline Savings in construction costs & $68.4 \%$ & $78.6 \%$ \\
\hline Greater economies of scale/efficiencies/integration & $65.2 \%$ & $73.8 \%$ \\
\hline Safety record & $64.2 \%$ & $84.5 \%$ \\
\hline Savings in design costs & $63.2 \%$ & $71.4 \%$ \\
\hline \hline
\end{tabular}

The private sector respondents also rated economies of scale and design cost savings as some of the least considered factors when hiring an external program manager. However, a large variation existed between the public and private sectors in their consideration of the safety record of an external program manager. The public sector respondents rated it as one of the least significant factors considered when selecting an external program manger while private sector respondents rated a provider's safety record as one of the factors most often considered when selecting a program manager. Private sector respondents considered the safety record of an external program 84.5 percent of the time during the hiring process placing it as one of their top four considerations. This difference in the importance placed on safety is possibly due to the fact that many public sector organizations cannot be sued, or if they are, their liability is often capped by law.

\section{Owner Organizational Model for Incorporating Program Management}

Finally research was conducted to determine what type of firm owners use most often to manage their construction program. The answer choices to determine the organizational model used most often when hiring an external program manager are as follows:

- Owner led, with program management firm providing staff support

- Integrated owner and program management team

- Program management consultant led

- Program management at-risk

- Other 
Figure 2 conveys the extent of the use of the various organizational models by both the public and private sector respondents.

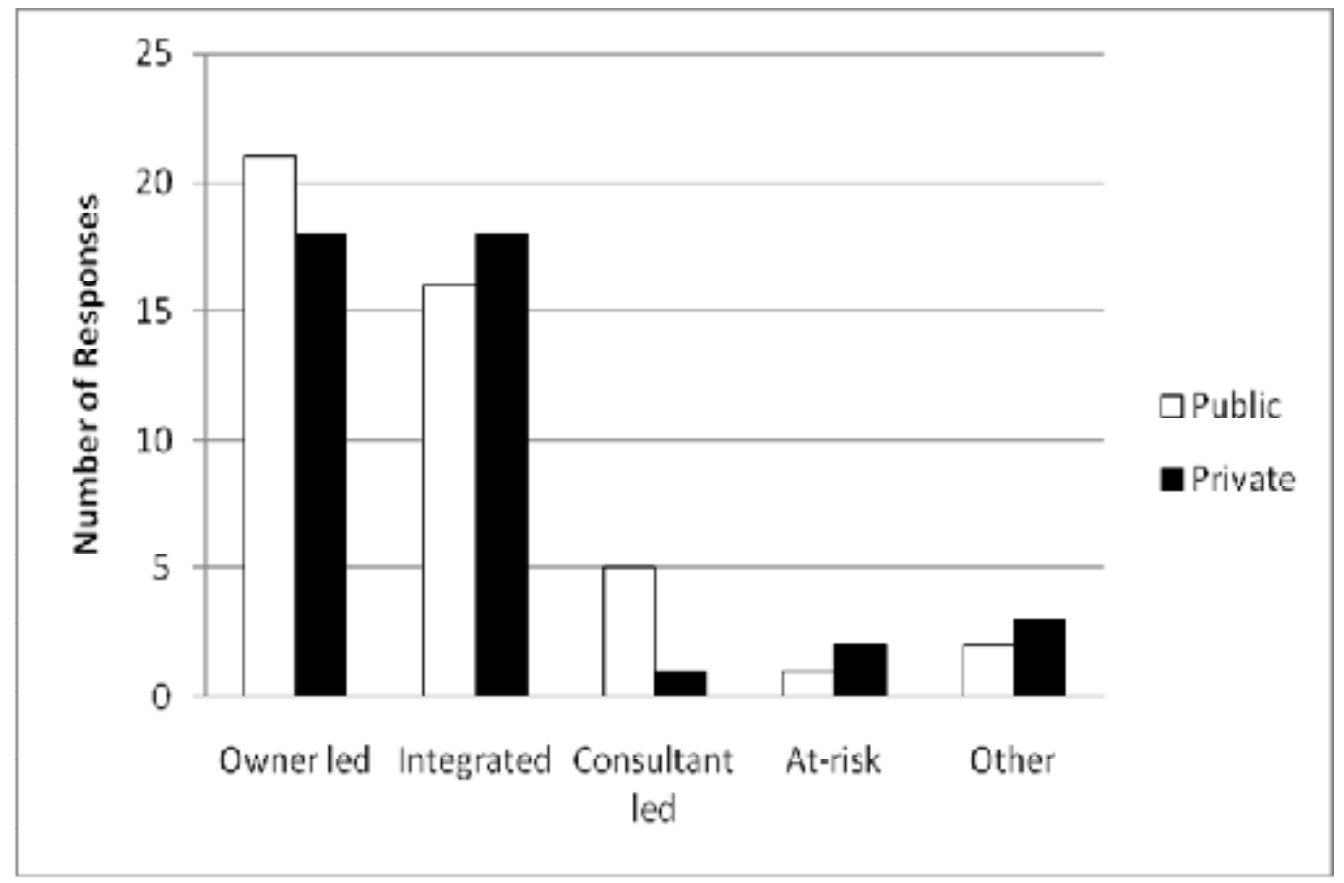

Figure 2: Organizational Models Used in Hiring an External Program Manager

As Figure 2 shows a total of 87 responses were recorded with 45 from the public sector and 42 from the private sector. The highest percentage of public sector respondents, 46.7 percent (21/45), reported using an organizational model that was owner led, with the program management firm providing staff support. The lowest percentage of public sector respondents, 2.2 percent (1/45), reported using a program management at-risk model.

The private sector was more evenly divided between owner led and integrated models with each receiving 43.0 percent $(18 / 42)$. Within the private sector the lowest percentage of private sector respondents, 2.4 percent (1/42), selected a consultant lead model.

As is evident from Figure 2 a large majority of owners, whether public or private, are using either an owner led or an integrated approach to program management (about 86 percent). Very few of the respondents in either sector are using consultant led or at-risk models.

\section{CONCLUSIONS}

The survey data indicates that private sector construction owners are more inclined to hire an external program manager than are public sector owners. Table 7 summarizes this survey data and helps to illustrate this point. It is clear from the table that $18.1 \%$ more of the private sector respondents reported having experience with hiring an external program manager than did the public sector. 
Table 7: Experience in Hiring an External Program Manager

\begin{tabular}{|c|c|c|}
\hline Survey Responses & Public & Private \\
\hline Total Number of Respondents & 99 & 71 \\
\hline Respondents with Experience in Hiring an External Program Manager & 49 & 48 \\
\hline Percent of Respondents With Experience in Hiring an External PM & $49.5 \%$ & $67.6 \%$ \\
\hline
\end{tabular}

When owners in either sector seek to procure the services of an outside firm to operate their construction program, they are in essence procuring program management services and must consider several issues including especially the following:

- The fee for hiring a program manager

- The type of firm providing the program management services

- The criteria for selecting a specific program manager

- The organizational model or relationship between the owner and the service provider

\section{Fees}

A review of the private and public fee data indicates a difference in the fees paid for an external program manager. Higher fees were reported by the private sector than by the public sector. The issue of higher program management fees, however, could be due to a lack of standardization throughout the construction industry. The functions that are performed by those who currently see themselves as program managers can vary significantly. Without knowing the exact functions associated with each reported fee, it is difficult to determine whether the fees are reasonable, or if they are being assessed on the same work. The actual survey question was as follows.

Of your annual construction spending identified in question 4 , what percentage is utilized to manage the process of construction (Combine both internal construction management and oversight costs with external or outsourced, program management, construction management, and oversight costs)?

Cost (Percentage of Annual Construction Spending): $\%$

The cost of management and oversight of the capital construction program was estimated by the firms using the above constraints. Referring to this as a fee is probably a misnomer in that we intentionally combined both the fees paid to external service providers and the internal overhead costs associated with serving as construction or program manager. This was done to normalize the responses and take into account the different construction oversight strategies. As an example, an owner that chooses to outsource significant portions of their program and project management responsibilities will have significant fees paid to external organizations. On the flip side, an organization that chooses to in-source large parts of their program will have much lower fees paid to external organizations and correspondingly higher overhead cost to perform the same program and project management responsibilities.

The way we segregated public and private organizations, was by splitting the firms based upon how they described themselves. There is no doubt that there are different scopes of work undertaken for project management and that this is one of the drivers of observed difference. 
The fact that we asked for both internal and external cost, however, should have tended to mute the observation of differences as in theory, there are a similar set of things that need to be done to manage any project. In reality, this is due in part to project delivery system differences observed in the public and private sector and also due to the likelihood that private owners are buying more services, higher value or quality services, and they are willing to pay more for access to these. On the public side, they are forced to buy these services in many instances in a competitive bid which results in frequently buying less service and lower value added service because the vast majority of the bid evaluation is focused on price. Another factor has to do with the wages paid to internal program management or project management staff versus the wages they can earn in the private sector. Across all public agencies, wages are not as high as wages that can be secured outside in the private sector. This wage difference will also drive the observation of higher private fees.

\section{Type of Service Provider}

With respect to the type of firm used in managing a construction program, respondents used a construction management firm most often when not using internal staff. The second most frequent choice for help was through the use of a program management firm. The public respondents appear to be more progressive in their use of program management firms to manage their construction programs as opposed to using construction management firms. Public organizations, particularly those having to do with the construction industry have for years moved more and more away from the performance of $\mathrm{X}$ (where $\mathrm{X}$ may represent design, construction, management, etc.) to the outsourcing of $\mathrm{X}$. This evaluation has been more prominent in the public sector. Private respondents, on the other hand, are still more likely to use a construction management firm.

\section{Selection Criteria}

When undertaking the process of hiring an external program manager, the criteria used for selecting the right service provider is extremely important. The criteria considered most often in selecting a program management service provider, as indicated by the survey respondents were:

- The provider had experience with similar projects and programs

- The provider's projects and programs are consistently delivered on time

- There was an individual lead program manager

None of the factors considered most often were related to cost. In fact the lowest rated criteria or factors considered when selecting a program management service provider were those related to cost. By providing low ratings for the factors related to cost, owners were demonstrating that they see program management as a value added service and not as a cost of commodity service.

The rating of one factor did, however, differ significantly between public and private respondents with respect to hiring. The public sector considered safety (or the safety record of the service provider) to be far less important than did private sector respondents. The legal environment associated with public and private construction should be considered as a possible explanation for the disparity. Many public organizations cannot be sued, while private organizations are wary of the threat of lawsuits. Since they do not have such a threat of lawsuits 
public construction owners are able to place more emphasis on other criteria when hiring an external program manager.

\section{Model}

Finally, it was determined that two organizational models are by far the most commonly used within when hiring an external program manager:

- Owner led management with the program manager providing staff support

- An integrated owner and program management team

Both of these models allow the owner to retain control of their construction program. Very few owners are willing to relinquish control of their construction program through either a program management consultant led relationship or a program management at-risk relationship. However, 9 percent (11 minus 2) more of the public sector respondents reported using a program management consultant led relationship than the private sector.

It is also important to note that only 2 percent (3/170) of the respondents to the survey reported using a program management at-risk model (see Figure 2). An at-risk contractual relationship is rarely seen when hiring an external program manager and it is heavily disputed as to whether or not a true at-risk relationship can even exist and still be defined as program management. Program management is considered by many within the industry to be a management technique and not a delivery method. We have most often seen the term program management at-risk used in the context of a delivery method and not a management technique. However, the fact that some of the respondents did report using a program management at-risk relationship demonstrates that some within the construction industry believe that a program management atrisk model is possible and are attempting to use it in practice.

\section{RECOMMENDATIONS}

Several recommendations for consideration by the construction industry were developed from the findings of this study and are offered here. First, the most critical need is to establish an industry wide standard definition for program management. Without a common understanding of this concept, it is difficult to develop any consensus about it. It is also difficult to design tests and develop metrics that enhance our understanding of it and that enable us to assess its performance. In fact, we recommend a workshop devoted to defining program management.

Such a workshop would initiate the kind of discussion needed to draw attention to this subject. Careful consideration would need to be given to those in attendance - members of the academic community, private and public owners, and those in the construction industry who are currently serving in a program management role. The workshop should then be followed by the development of an initial document that could be presented in training sessions through numerous venues. Thus, materials and discussion, and revisions, would eventually drive the emergence of a general understanding of program management.

Second, the difference in fee totals found in this paper conveys the fact that it is difficult to determine an appropriate fee for program management services when the services offered under 
the umbrella of program management are not standardized. Owners within the construction industry struggle with this same issue. Without a standardized definition for program management and an agreed upon set of functions to be performed by a program manager it is difficult for owners to determine if they are getting a fair price when procuring program management services.

Also, program management should be considered to be a different service than construction management and owners should seek to hire firms with experience in managing the entire construction program. Those firms who specialize in construction management, but have experiences only on construction projects rather than construction programs, may not actually be capable of managing a construction program.

Finally, of importance for the future of program management, especially with respect to the hiring of an external program manager, will be certification. While certification exists for construction managers through CMAA, certifying program managers should be established. Construction managers may have the closest skill set needed to manage a construction program, but it is imperative for firms with this ability to designate themselves as program managers. The designation should not be subjective. Program managers should be certified and their certification should be backed by a professional organization such as CMAA.

\section{ACKNOWLEDGEMENT}

The writers would like to especially thank CMAA and director Bruce D'Agostino for their continued support of the FMI/CMAA Survey of Owners. Mr. D'Agostino's guidance was invaluable in providing access to industry professionals and in the development and execution of the survey. The writers would also like to thank the program management focus group and each professional organization that participated in the survey including COAA, CURT, HFI, and CEFPI.

\section{REFERENCES}

Bridgers, M. and D'Agostino, B. (2006). "FMI/CMAA Seventh Annual Survey of Owners." FMI Corporation.

Comstruction Management Association of America (CMAA) (2008). "What is Construction Management?" Construction Management Association of America, <http://cmaanet.org/cma is.php > (Sept. 11, 2008).

Datamonitor. (2006). "Construction \& Engineering in the United States: Industry Profile." Datamonitor, New York, New York.

Galloway, P. D. (2006). "Survey of the Construction Industry Relative to the Use of CPM Scheduling for Construction Projects." Journal of Construction Engineering and Management, ASCE, Volume 132, Number 7, Pages 697-711.

Gordon, C. (1994). "Choosing Appropriate Construction Contracting Method." Journal of Construction Engineering, ASCE, Volume 120, Number 1, Pages 196-210. 
Hansen, K. and Vanegas, J. (2005). "Emerging Methods for Defining and Managing Dynamic Project Requirements." Construction Research Congress, ASCE, San Diego, CA.

Kenig, M., Donohue, D., Haire, D., Hill, D., Martin, S., Poppe, R., and Shapiro, S. (2004). "Project Delivery Systems for Construction: 2nd Edition." Associated General Contractors of America, United States of America, 3-25.

Kumaraswamy, M., Ling, F., Rahman, M., and Phng, S. (2005). "Constructing Relationally Integrated Teams." Journal of Construction Engineering and Management, ASCE, Volume 131, Number 10, Pages 1076-1086.

Grasso, B., Rasdorf, W., and Bridgers, M., "The Nature and Extent of Domestic Construction Program Outsourcing," Journal of Construction Engineering and Management, American Society of Civil Engineers, Volume 134, Number 12, Pages 1002-1010 (December 2008).

Simonson, K. (2006). "Quick Facts about the Construction Industry." Associated General Contractors of America.

Yun, G. W. and Trumbo, C. W. (2000). "Comparative Response to a Survey Executed by Post, E-Mail, and Web Form," Journal of Computer-Mediated Communication, Indiana University School of Library and Information Science, Volume 6, Number 1. 